\title{
CHRONIC BACK PAIN - EFFECTS OF THE STABILIZATION EXERCISES ON PAIN, RANGE OF MOTION AND FUNCTIONAL DISABILITY, THE MANAGEMENT OF THE PATIENTS
}

\author{
Surven Metolli, \\ Aisel Oseku ${ }^{i}$ \\ Sports University of Tirana, \\ Albania
}

\begin{abstract}
:
Background: The worldwide prevalence of chronic spinal pain is $19.6 \%$ in them aged 1923 years and more prevalent in females. Routine physiotherapy seems to be effective in reducing pain and improving functional outcome in patients with chronic back pain. Back stabilization exercises are in trend in the management of chronic pain, it is not known whether the addition of these exercises produces better results even though the patient has pain during execution. Objective: The aim of this study was to determine the effect of back stabilization exercises on pain, ROM and functional inability to manage chronic back pain. A random trial in: Period: February 2021 to July 2021. Methods: 42 patients with back pain ( 3 patients dropped out of the study). Participants were recruited through intentional sampling technique. The tools used for data collection were NPRS, Modified ODI, Goniometry (Lumbar Bending, stretching and lateral bends) and MMT (Trunk Flexors and Clamps). The data were analyzed at the beginning and later after 2 weeks of intervention (8 sessions). Results: 20 males and 19 females participated in the study. After 2 weeks of intervention this treatment showed improvement in reducing pain and improving functional status. SE had shown significant gains in NPRS $p=0.001$, modified ODI $\mathrm{p}=0.001$, ROM Extension $\mathrm{p}=0.027$, ROM Curvature on the right side $\mathrm{p}=$ 0.024 and MMT Flexion $p=0.031$. Conclusion: Stabilization exercises have been found to be effective in managing chronic back pain in terms of pain reduction and functional inability.
\end{abstract}

Keywords: chronic back pain, stabilization exercise, range of motion, functional disability, patients' management

i Correspondence: email smetolli@ust.edu.al; aoseku@ust.edu.al 


\section{Introduction}

Previous research has shown that back pain is a universal experience; approximately every person experiences this pain once in their lifetime. It's mostly the most common reason behind work-related disability. In 2010, back pain was labeled as one of the most common reasons for health care visits among musculoskeletal disorders. People of all ages, ethnicities, genders and demographic areas all over the globe are affected by back pain, where most of those affected are female. When it comes to the spread of back pain in general the literature available is sufficient on the other hand very little information is present when it is about chronic back pain because there are different schools of thought regarding the definition of chronic back pain. According to some it is called chronic back pain the pain that lasts more than 7-12 weeks while others classify recurrent back pain as chronic pain after affecting an individual for a long period, finally for some chronic back pain is pain lasting longer than the expected period of healing.

Therapeutic Exercises for Back Pain (BP) have advanced over time. the main purpose of the exercises is to stabilize the lumbar spine and hold it. Essential, or segmental stabilization is a multi-ingredient exercise program aimed at improving strength, flexibility and endurance. These active forms of exercises are designed to strengthen muscles, to support back and help prevent back pain. In general, can be described in back pain management episode at any time or after a detail assessment of the patient's condition. The back muscles are exercised to teach the spine how to stand on this position. Some muscle groups are targeted, mainly abdominis transversus $(\operatorname{TrA})$, lumbar multifidi, lumbar paraspinal, abdominal, diaphragmatic, and pelvic musculature.

Figure 1: Therapeutic Exercises for Back Pain (BP)

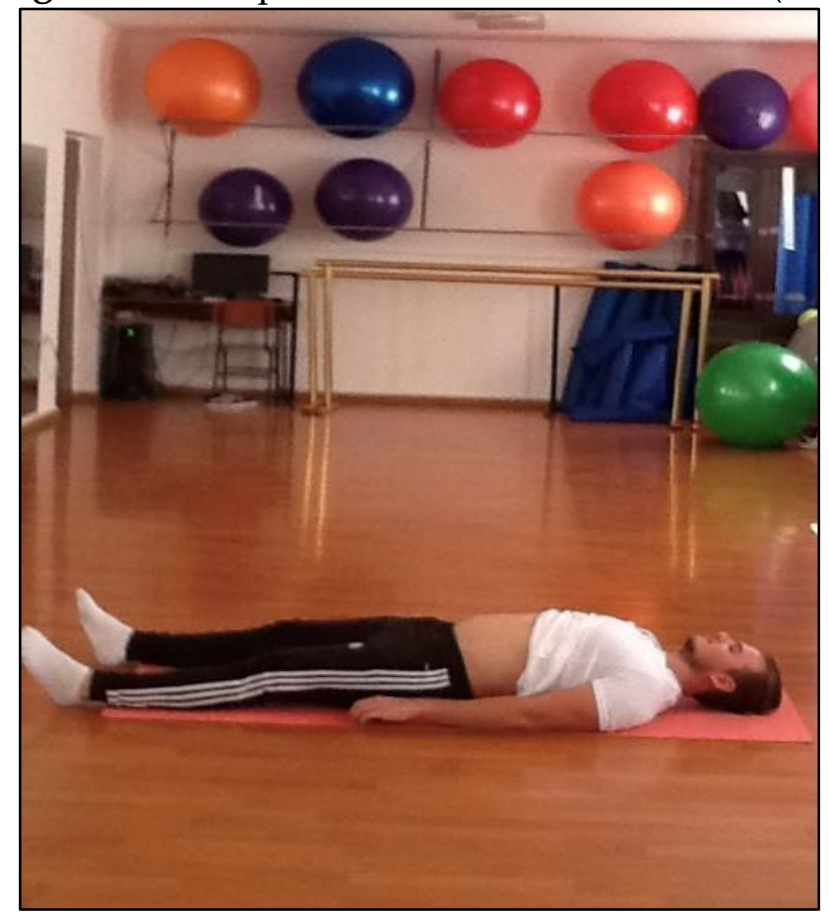

Source: Author's collection 
The first stabilization training program for transverse activation and strengthening the abdominal and multifidus muscles were introduced by Richardson et al. The basic concept was in relation to lumbar spine stability; according to them stability is influenced by power and TrA and lumbar MF muscle endurance, strengthening of these stabilizing muscles affects in reducing pain and improving functionality. For TrA activation and lumbar mulifidus muscle patients are instructed to lie on their backs and to press the abdominal button during exhalation. While the patient is contracted isometrically abdominal muscle transversus abdominis and lumbar multifidus are coactivated. If the patient has difficulty activating and transverse abdominis, pressure biofeedback unit can be used for learning as it gives visual feedback. Another study in 2004 on the effect of lumbar stabilization training on functional ability and quality of life in patients with chronic back pain suggested a lumbar stabilization program which has been found to be effective in improving the quality of life and functional outcome in patients with CBP.

\section{Materials and Methods}

A random trial was conducted from February 2021 to July 2021 at the Sports University of Tirana. Thirty nine patients diagnosed with back pain were included in the study; their symptoms were present for more than 3 months with limited ROM and aged between 19-23. Patients with prolapsed intervertebral disc, spinal fracture, inflammatory condition, mass occupying lesion and radicular symptoms below knee were excluded from the study. Each patient underwent a semi-structured questionnaire. The first part of the questionnaire consisted of demographic data including the name of patient, age, gender, current address, contact number, profession. Patients then asked about their current symptoms, onset of their pain (duration), aggravating factors, mitigating factors, drug use, any previous medication taken. Finally, the patient was asked to report any previous physiotherapy treatment for managing their back pain. All the patients were assessed at baseline with NPRS (numeric pain rating scale), MMT (Trunk Flexors and Extensor), ROM (Lumbar Flexion, Extension and Side bendings) and Modified ODI prior to first treatment session and later at the end of last treatment session. A total of 8 treatment sessions were given the patients, 4 days per week for two weeks. The data was analyzed at baseline and later after 2 weeks of intervention (8 sessions) on Anova t- and $\mathrm{z}$ - tests methods.

\section{Results}

A total of 42 chronic low back pain patients (03 drop out) participated in the study. The participants were recruited through non-probability purposive sampling technique. Out of 39 patients 19 were females and 20 males. Most of the patient (62\%) reported onset of low back pain for more than a year. The most common stated aggravating factor was pain progression with the day i.e. $35 \%$ next to it was prolong sitting and bending $27.5 \%$ each. 
Overall, $87.5 \%$ of patients already took medicines for the relief of their symptoms. Test results showed the $\mathrm{p}$ value for NPRS was $<.001$ which was significant. The $\mathrm{p}$ value for Modified ODI was <.001 which was significant. The $\mathrm{p}$ value for ROM Flexion was $<.001$ which was significant. The $\mathrm{p}$ value for ROM Extension was $<.001$ which was significant. The $\mathrm{p}$ value for ROM Right Side Bending was .002 which was significant. The $\mathrm{p}$ value for ROM Left Side Bending was .003 which was significant. The results were not significant for MMT Trunk Flexors with $\mathrm{p}$ value of 1.000. The $\mathrm{p}$ value for MMT Trunk Extensors was .317 .

Table 1:

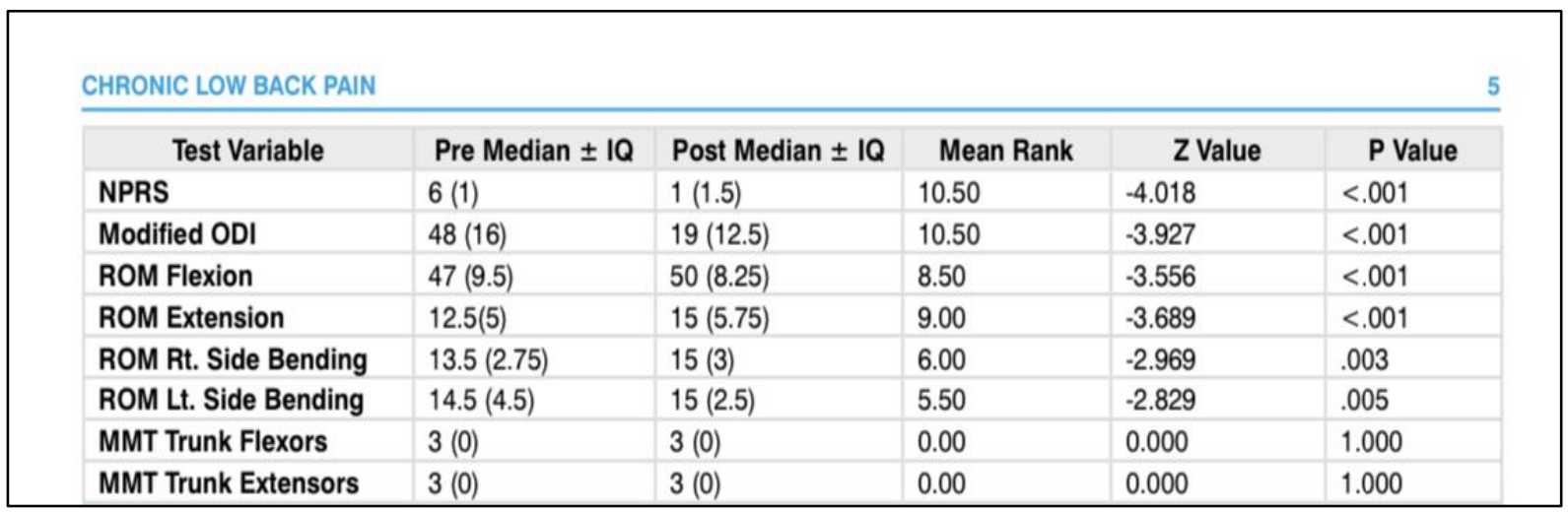

\section{Conclusion}

This study suggests that lumbar stabilization exercises is effective in the management of chronic back pain in terms of reducing pain and improving functional status. Literature also supports that lumbar stabilization exercises lessen pain and improves functional status of patients with chronic back pain.

High physical activity was associated with the risk of having BP, length of time with BP, and disability due to BP. Future studies should focus on the exercise regimens, clinical treatment, and clinical diagnosis of female subjects and adolescent athletes with more than 6 hours / week of leisure sports activity.

\section{Conflict of Interest Statement}

The authors declare no conflicts of interests.

\section{About the Authors}

Surven Metolli is a Lecturer / Head of Health and Movement Department, Faculty of Physical Activity and Recreation, Sports University of Tirana. Received a Science Degree in General Medicine from the Faculty of Medicine, University of Tirana. Current research interest the physical rehabilitation after mechanical traumas.

Aisel Oseku is a Lecturer/ Assistant Professor, Department of Biomedical and Humanities Disciplines, Faculty of Sciences and Rehabilitation, Sports University of Tirana. Bachelor Degree in Physiotherapy Science from the (University Our Lady of Good Counsel) 
Tirana, Albania. Current research interest the physical capabilities, body type, and activity level in order to prescribe exercise and other physical means to help improve function.

\section{References}

Andersson GB. Epidemiological features of chronic back pain. The Lancet. 1999;354(9178):581-5.

Charles G. (Chad) Helmick M. The Burden of Musculoskeletal Diseases in the United States (BMUS). United States of America 2014 [cited 201624 July]; 4th:[Available from: http://www.boneandjointburden.org.

Cairns MC, Foster NE, Wright C. Randomized controlled trial of specific spinal stabilization exercises and conventional physiotherapy for recurrent low back pain. Spine. 2006;31(19):E670-E81.

França FR, Burke TN, Hanada ES, Marques AP. Segmental stabilization and muscular strengthening in chronic low back pain: a comparative study. Clinics. 2010;65(10):1013-7.

Gunnar Andersson M, PhD. United States Bone and Joint Initiative: The Burden of Musculoskeletal Diseases in the United States (BMUS). 2014 [cited 20165 August]; Third Edition:[Available from: http://www.boneandjointburden.org/2014report/iid0/burden-back-pain.

Hoy D, Bain C, Williams G, March L, Brooks P, Blyth F, et al. A systematic review of the global prevalence of low back pain. Arthritis \& Rheumatism. 2012;64(6):2028-37.

Richardson C, Jull G, Hodges P, Hides J. Therapeutic Exercise for Spinal Segmental Stabilization in Low Back Pain: Scientific Basis and Clinical Approach. 1999.

Standaert CJ, Weinstein SM, Rumpeltes J. Evidence informed management of chronic low back pain with lumbar stabilization exercises. The spine journal. 2008;8(1):114-20.

Stankovic A, Lazovic M, Kocic M, Dimitrijevic L, Stankovic I, Zlatanovic D, et al. Lumbar stabilization exercises in addition to strengthening and stretching exercises reduce pain and increase function in patients with chronic low back pain: randomized clinical open label study. life. 2012;2:3.

Shaughnessy M, Caulfield B. A pilot study to investigate the effect of lumbar stabilisation exercise training on functional ability and quality of life in patients with chronic low back pain. International journal of rehabilitation research. 2004;27(4):297-301.

Tandaert CJ, Weinstein SM, Rumpeltes J. Evidence informed management of chronic low back pain with lumbar stabilization exercises. The spine journal. 2008;8(1):114-20.

Wang X-Q, Zheng J-J, Yu Z-W, Bi X, Lou S-J, Liu J, et al. A meta-analysis of core stability exercise versus general exercise for chronic low back pain. PloS one. 2012;7(12):e52082. 
Creative Commons licensing terms

Authors will retain the copyright of their published articles agreeing that a Creative Commons Attribution 4.0 International License (CC BY 4.0) terms will be applied to their work. Under the terms of this license, no permission is required from the author(s) or publisher for members of the community to copy, distribute, transmit or adapt the article content, providing a proper, prominent and unambiguous attribution to the authors in a manner that makes clear that the materials are being reused under permission of a Creative Commons License. Views, opinions and conclusions expressed in this research article are views, opinions and conclusions of the author(s). Open Access Publishing Group and European Journal of Physical Education and Sport Science shall not be responsible or answerable for any loss, damage or liability caused in relation to/arising out of conflict of interests, copyright violations and inappropriate or inaccurate use of any kind content related or integrated on the research work. All the published works are meeting the Open Access Publishing requirements and can be freely accessed, shared, modified, distributed and used in educational, commercial and non-commercial purposes under a Creative Commons attribution 4.0 International License (CC BY 4.0). 